\title{
Chondrolipoma of the finger in a child: A case study
}

\author{
KAZUYOSHI MITANI ${ }^{1}$, TERUYA KAWAMOTO ${ }^{1,2}$, HITOMI HARA ${ }^{1}$, NAOMASA FUKASE ${ }^{1}$, \\ YOHEI KAWAKAMI ${ }^{1}$, MASAYUKI MORISHITA ${ }^{3}$, TOSHIYUKI TAKEMORI ${ }^{1}$, SHUICHI FUJIWARA ${ }^{1}$, \\ KAZUMICHI KITAYAMA ${ }^{1}$, SHUNSUKE YAHIRO ${ }^{1}$, TOMOHIRO MIYAMOTO ${ }^{1}$, MASATO KOMATSU ${ }^{4}$, \\ NAOE JIMBO $^{4}$, RYOSUKE KURODA ${ }^{1}$ and TOSHIHIRO AKISUE ${ }^{1,5}$ \\ ${ }^{1}$ Department of Orthopaedic Surgery, Kobe University Graduate School of Medicine, Kobe, Hyogo 650-0017; \\ ${ }^{2}$ Division of Orthopaedic Surgery, Kobe University Hospital International Clinical Cancer Research Center, Kobe, \\ Hyogo 650-0047; ${ }^{3}$ Department of Orthopaedic Surgery, Hyogo Cancer Center, Akashi, Hyogo 673-0021; \\ ${ }^{4}$ Department of Diagnostic Pathology, Kobe University Graduate School of Medicine, Kobe, Hyogo 650-0017; \\ ${ }^{5}$ Department of Rehabilitation Science, Kobe University Graduate School of Health Sciences, Kobe, \\ Hyogo 654-0142, Japan
}

Received June 12, 2020; Accepted September 19, 2020

DOI: $10.3892 / \mathrm{mco} .2020 .2164$

\begin{abstract}
Chondrolipoma is, based on the limited case reports available, an extremely rare histological variant of lipoma with the proliferation of mature adipocytes containing an area of true hyaline cartilage. Chondrolipoma is characterized by adult onset and is often identified in the breast, pharynx and tongue. The current study presents a case of chondrolipoma of the finger in an 11 year-old girl. Physical examination indicated a well-defined elastic soft mass, measuring $2.5 \times 2 \mathrm{~cm}$, on the dorsal aspect of the proximal phalanx of the left middle finger. Magnetic resonance imaging (MRI) revealed a well-circumscribed lesion with heterogeneous signal intensity. On T1- and $\mathrm{T} 2$-weighted images, the lesion indicated a predominantly marked hyperintense signal containing linear hypointense regions, and on fat-suppressed short-tau inversion recovery sequences, the lesion indicated a predominant hypointensity, with linear regions displaying hyperintensity. Marginal excision of the tumor was performed. Histologically, the major component of the tumor was mature adipose tissue containing a limited area of mature hyaline cartilage matrix, without lipoblasts or malignancy. The postoperative course of the patient was excellent, with no local recurrence three years after surgery. To the best of our knowledge, the current study outlines the first pediatric case of chondrolipoma arising in the finger.
\end{abstract}

Correspondence to: Dr Teruya Kawamoto, Department of Orthopaedic Surgery, Kobe University Graduate School of Medicine, 7-5-1 Kusunoki-cho, Chuo-ku, Kobe, Hyogo 650-0017, Japan

E-mail: trykwmt@med.kobe-u.ac.jp

Key words: chondrolipoma, lipoma, child, finger, magnetic resonance imaging

\section{Introduction}

The current World Health Organization (WHO) classification of soft tissue and bone tumors includes 13 types of benign adipocytic tumors, of which lipoma is the most common (1). The mesenchymoma was originally defined by Stout in 1948 to describe a tumor containing at least two mesenchymal tissues, not usually found together, in addition to fibrous elements (2), and lipomas occasionally contain other mesenchymal elements, for example, osseous tissue, fibrous tissue, or smooth muscle, and are classified as osteolipoma (3-5), fibrolipoma (6-8) or myolipoma $(9,10)$, respectively. Lipomas can contain cartilage metaplasia, which is referred to as chondrolipoma, a rare form of benign mesenchymoma. Sporadic case reports of chondrolipoma in adults exist; however, pediatric presentation is extremely rare (11). Chondrolipomas frequently present in the breast, pharynx, and tongue (12-18), and there is no previous report of a chondrolipoma arising in the finger.

We present a rare case of a chondrolipoma of the finger in an 11-year-old girl, with a review of the corresponding magnetic resonance imaging (MRI) and pathological findings. To our knowledge, this is the first pediatric case report of chondrolipoma arising in the finger. The patient and her family were informed that data from the case would be submitted for publication and gave us consent for the academic use of clinical information.

\section{Case report}

An 11-year-old girl was referred to the Kobe University hospital on March 2017, with a painless mass on the dorsal aspect of the proximal phalanx of her left middle finger, which she had noticed a year ago after catching the finger in a closing door. Clinical examination revealed a well-defined elastic soft mass, measuring $2.5 \times 2 \mathrm{~cm}$, with no associated redness, local heat nor tenderness, and the lesion was mobile without fixation to overlying skin or deeper structures. 


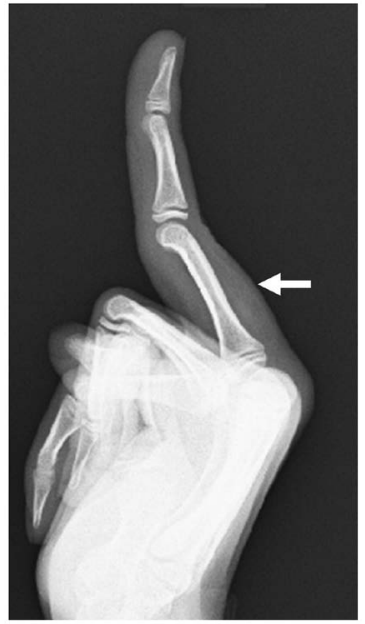

Figure 1. A preoperative radiograph of the left middle finger. White arrow, soft tissue mass without evidence of calcification or bone erosion.

\section{A}

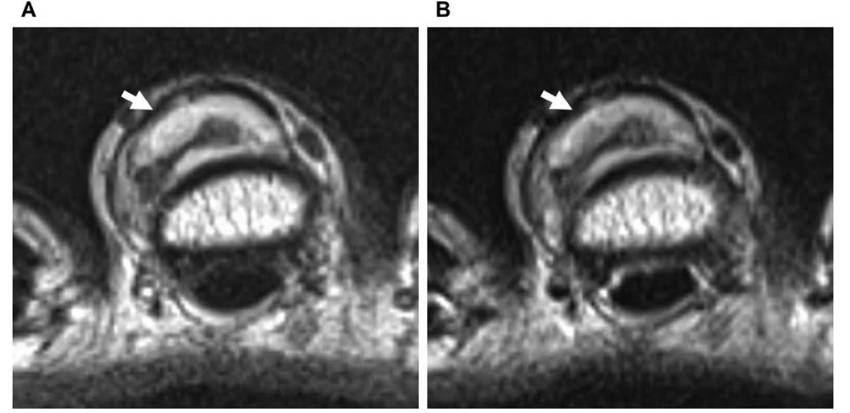

Figure 2. Preoperative axial (A) T1- and (B) T2- weighted magnetic resonance imaging (MRI) of the left middle finger showing a soft tissue mass with high-signal intensity containing additional area of low-signal intensity (white arrows).

The functions of the finger including range of motion and sensation were not impaired. A plain radiograph of the left middle finger revealed a soft tissue mass without evidence of a calcification and a bone erosion (Fig. 1). MRI revealed a well-circumscribed $2.5 \times 2 \times 1 \mathrm{~cm}$-sized lesion with heterogeneous signal intensity. On both T1- and T2-weighted images, the lesion showed a predominantly marked hyperintense signal containing linear hypointense regions (Figs. 2 and 3A), and on fat-suppressed short-tau inversion recovery (STIR) sequences, the lesion showed a predominant hypointensity, with linear regions displaying hyperintensity (Fig. 3B). MRI findings suggested a diagnosis of lipoma with non-adipose elements, such as cartilage matrix.

During marginal resection, a well-circumscribed tumor was found on the extensor tendon without adhesion to surrounding structures. Histologically, the major component of the tumor was mature adipose tissue, with a limited area of hyaline cartilage matrix which included the flat/asteroid form cell (Fig. 4). Alcian blue staining was moderately positive in the cartilage matrix (Fig. 5). There were no lipoblasts or histological features of malignancy, and the histopathological diagnosis was a chondrolipoma. The patient experienced excellent recovery, without any functional impairment or local recurrence three years after surgery.

A
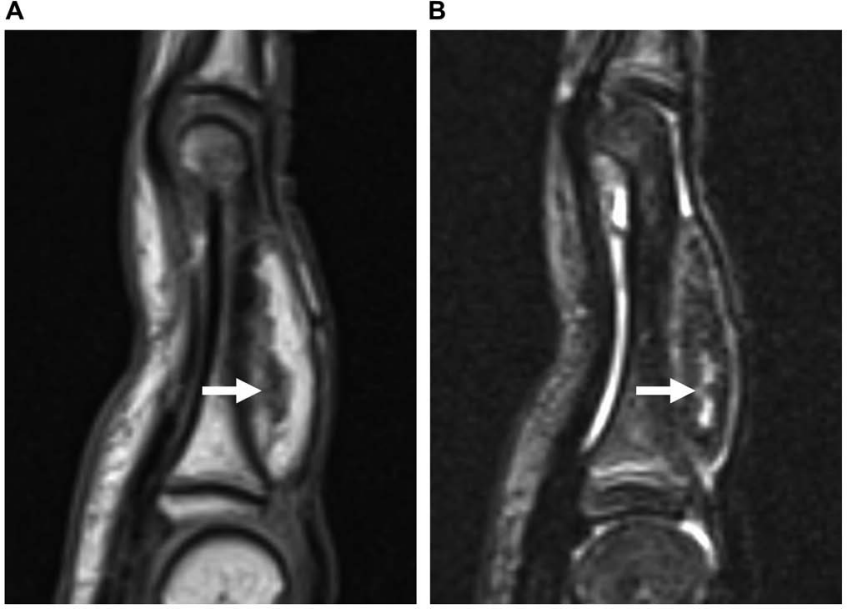

Figure 3. Preoperative sagittal magnetic resonance imaging (MRI) of the left middle finger. The soft tissue mass possesses low-signal intensity area on (A) T1-weighted image (white arrow) and high-signal intensity area on (B) short-tau inversion recovery image (white arrow).

A

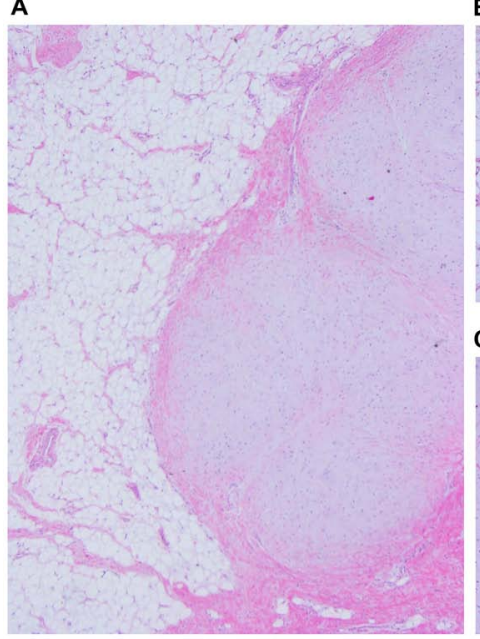

Figure 4. Histopathological images of the resected tumor. (A) Major component of the tumor is mature adipose tissue with limited hyaline cartilage matrix. Hematoxylin-eosin staining. Magnification, x20. (B) Mature adipose area. Hematoxylin-eosin staining. Magnification, x20. (C) Mature hyaline cartilage matrix area. Hematoxylin-eosin staining. Magnification, x20.

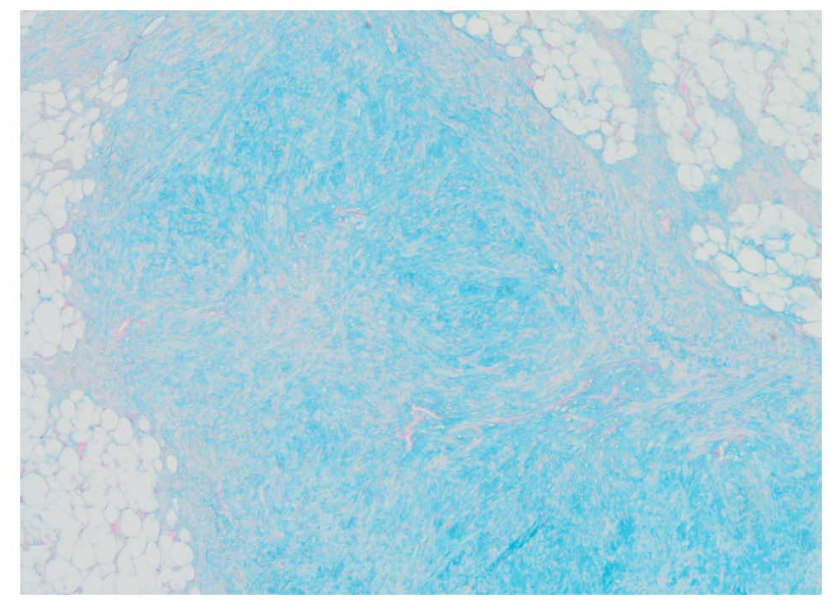

Figure 5. Alcian blue staining of the resected tumor. Magnification, x20. The cartilage matrix is moderately positive, as indicate using alcian blue staining. 


\section{Discussion}

Chondrolipoma is often confused with chondroid lipoma, a subtype of benign adipocytic tumors, because of the terminological similarity. Histologically, chondroid lipomas have tumor cells with central irregular nuclei surrounded by clear vacuolated cytoplasm resembling lipoblasts without mature hyaline cartilages $(1,16-21)$. However, in the present case, characteristic features of coexisting areas with lipoma and true hyaline cartilage, with no evidence of lipoblasts, resulted in diagnosis of chondrolipoma.

Controversy exists regarding chondrolipomas' etiology, with two predominant theories regarding its developmental mechanisms. One posits that pluripotent mesenchymal cells differentiate into both adipose and cartilage cells, and another postulates that lipomas obtain chondrometaplasia following traumatic injury (19). In this case, the tumor development was probably triggered when the finger caught in the door. Signorini et al. discussed the pathogenetic mechanisms of post-traumatic lipomas, suggesting the differentiation of mesenchymal precursors (preadipocytes) to mature adipocytes by a trauma as a possible mechanism (22). Copcu and Sivrioglu reported fat necrosis as the major etiological factor in post-traumatic subcutaneous lipomas (23). Furthermore, Copcu and Sivrioglu mentioned that soft tissue trauma could result in hematoma formation, subsequent lymphatic effusion, and the formation of lipomatous lesions (23). Since the finger has limited space, this may explain how a post-traumatic hematoma caused pluripotent mesenchymal cells to differentiate into both adipose and cartilage cells simultaneously, then eventually forming a chondrolipoma. Therefore, obtaining a history of trauma is invaluable in diagnosing this neoplasm.

The characteristic histopathological feature of chondrolipoma is coexisting mature adipose tissue and hyaline cartilage $(1,11-18,24)$. Lipomas typically show high-signal intensity on both T1-and T2-weighted MRI, compared to iso-signal intensity on the fat-suppressed sequence. In contrast, hyaline cartilage reveals low-signal intensity on T1-weighted images and higher-signal intensity on STIR sequences, which reflect high ratios of the water content within the cartilage component. Pathological and MRI evidence pointed to the diagnosis of this rare variant of lipoma; that is, there were contrasting signal intensities between cartilage and adipose components on T1-weighted and STIR images, respectively. The STIR sequence of MRI examination, which has recently been widely used in musculoskeletal imaging, is a valuable diagnostic tool for chondrolipoma. Despite the difficulty in diagnosis, local recurrence or malignant transformation following resection has never been reported in the literature $(11-18,24)$, suggesting that the therapeutic strategy for chondrolipoma should be consistent with that of lipoma. Given that, a wait-and-see policy for chondrolipomas should be acceptable, depending on the size and location.

In conclusion, we describe an unprecedented case of pediatric chondrolipoma arising in the finger, and identified the characteristic MRI appearances in T1- and T2-weighted, and STIR images. Clinicians should consider chondrolipoma as a differential diagnosis when they come across such characteristic MRI findings in patients with history of trauma, as this may be beneficial for treatment strategies.

\section{Acknowledgements}

Not applicable.

\section{Funding}

No funding was received.

\section{Availability of data and materials}

The datasets used and/or analyzed during the present study are available from the corresponding author or reasonable request.

\section{Author's contributions}

KM and TK designed the experiments and wrote the initial draft of the manuscript. MK, TK and HH performed the surgery of the lesion. NF, YK, MM, TT, SF, KK, SY and TM provided medical care for the patients and collected the data. MK and NJ performed histological examinations of the tumor tissue. RK and TA were responsible for the design and interpretation of the study as well as revisions and approval of the final draft of the manuscript. All the authors have read and approved the final version of the manuscript.

\section{Ethics approval and consent to participate}

Not applicable.

\section{Patient consent for publication}

The patient and her family were informed that data from the case would be submitted for publication and gave us consent for the academic use of clinical information.

\section{Competing interests}

The authors declare that they have no competing interests.

\section{References}

1. Fletcher CD, Bridge JA, Hogendoorn P and Mertens F: WHO Classification of Tumours of Soft Tissue and Bone. 4th edition. IARC Press, Lyon, pp19-30, 2013.

2. Stout AP: Mesenchymoma, the mixed tumor of mesenchymal derivatives. Ann Surg 127: 278-290, 1948.

3. Kwan Ip NS, Lau HW, Wong WY and Yuen MK: Osteolipoma in the forearm. J Clin Imaging Sci 8: 20, 2018.

4. Demiralp B, Alderete JF, Kose O, Ozcan A, Cicek I and Basbozkurt M: Osteolipoma independent of bone tissue: A case report. Cases J 2: 8711, 2009.

5. Fritchie KJ, Renner JB, Rao KW and Esther RJ: Osteolipoma: Radiological, pathological, and cytogenetic analysis of three cases. Skeletal Radiol 41: 237-244, 2012.

6. Lee JH and Oh DH: Fibrolipoma in an unusual location: The nasopharynx. Ear Nose Throat J 98: 66-67, 2019.

7. Sethia R, Rawlins KW, Aljasser A, Nogan S, Elmaraghy CA and Wiet GJ: Pediatric nasopharyngeal fibrolipoma: A case report and review of the literature. Int J Pediatr Otorhinolaryngol 125: 103-106, 2019.

8. Shin SJ: Subcutaneous fibrolipoma on the back. J Craniofac Surg 24: 1051-1053, 2013. 
9. Meis JM and Enzinger FM: Myolipoma of soft tissue. Am J Surg Pathol 15: 121-125, 1991.

10. Fukushima M, Schaefer IM and Fletcher CD: Myolipoma of soft tissue: Clinicopathologic analysis of 34 cases. Am J Surg Pathol 41: 153-160, 2017.

11. Ishibashi T, Nishio J, Kobayashi S, Shiramizu K and Yamamoto T: Chondrolipoma of the ankle in a child: A case report. J Foot Ankle Surg 56: 1284-1287, 2017.

12. Boltze C, Hribaschek A,Lippert H and Roessner A: Intermuscular chondrolipoma of the thigh: The diagnostic way of a rare entity. Pathol Res Pract 199: 503-507, 2003.

13. Fushimi H, Kotoh K, Nishihara K, Fujinaka H and Takao T: Chondrolipoma of the breast: A case report with cytological and histological examination. Histopathology 35: 478-479, 1999.

14. Halaas YP, Mra Z and Edelman M: Chondrolipoma of the oropharynx. Ear Nose Throat J 80: 146-147, 2001.

15. Tomonaga $\mathbf{M}$ and Kudawara I: Ossifying chondrolipoma of the thigh: Radiographic pathologic correlation. Curr Orthop Pract 25: 493-496, 2014.

16. Raj V, Dwivedi N, Sah K and Chandra S: Chondrolipoma: Report of a rare intra oral variant with review of histiogenetic concepts. J Oral Maxillofac Pathol 18: 276-280, 2014.

17. Özer $\mathrm{F}$ and Bal N: A rare diagnosis in the neck during childhood: Congenital chondrolipoma. Turk Patoloji Derg 33: 161-163, 2017.

18. Nonaka CF, Miguel MC, de Souza LB and Pinto LP Chondrolipoma of the tongue: A case report. J Oral Sci 51: 313-316, 2009.

19. Katzer B: Histopathology of rare chondroosteoblastic metaplasia in benign lipomas. Pathol Res Pract 184: 437-445, 1989.
20. Goldblum JR, Weiss SW and Folpe AL: Enzinger and Weiss's Soft Tissue Tumors. 6th edition. Mosby, St. Louis, MO, pp452-455 2014.

21. Meis JM and Enzinger FM: Chondroid lipoma. A unique tumor simulating liposarcoma and myxoid chondrosarcoma. Am J Surg Pathol 17: 1103-1112, 1993.

22. Signorini M and Campiglio GL: Posttraumatic lipomas: Where do they really come from? Plast Reconstr Surg 101: 699-705, 1998.

23. Copcu E and Sivrioglu NS: Posttraumatic lipoma: Analysis of 10 cases and explanation of possible mechanisms. Dermatol Surg 29: 215-220, 2003.

24. Nakano M, Arai E, Nakajima Y, Nakamura H, Miyazono K and Hirose T: Immunohistochemical study of chondrolipoma: Possible importance of transforming growth factor (TGF)-betas, latent TGF-beta binding protein-1 (LTBP-1), and bone morphogenetic protein (BMP) for chondrogenesis in lipoma. J Dermatol 30: 189-195, 2003.

This work is licensed under a Creative Commons Attribution-NonCommercial-NoDerivatives 4.0 International (CC BY-NC-ND 4.0) License. 